\title{
Effects of Age, Age-Related Hearing Loss, and Contralateral Cafeteria Noise on the Discrimination of Small Frequency Changes: Psychoacoustic and Electrophysiological Measures
}

\author{
Sibylle Bertoli, ${ }^{1}$ Jacek Smurzynski, ${ }^{2}$ and Rudolf Probst ${ }^{1}$ \\ ${ }^{1}$ Department of Otorhinolaryngology, University Hospital, CH-4031, Basel, Switzerland \\ ${ }^{2}$ Department of Communicative Disorders, East Tennessee State University, Johnson City, TN 37614, USA
}

Received: 22 April 2004; Accepted: 25 March 2005; Online publication: 19 July 2005

\begin{abstract}
The aim of the study was to examine central auditory processes compromised by age, age-related hearing loss, and the presentation of a distracting cafeteria noise using auditory event-related potentials (ERPs). In addition, the relation of ERPs to behavioral measures of discrimination was investigated. Three groups of subjects participated: young normal hearing, elderly subjects with normal hearing for their age, and elderly hearing-impaired subjects. Psychoacoustic frequency discrimination thresholds for a $1000-\mathrm{Hz}$ pure tone were determined in quiet and in the presence of a contralateral cafeteria noise. To elicit ERPs, small frequency contrasts were presented with and without noise under unattended and attended conditions. In the attended condition, behavioral measures of $d^{\prime}$ detectability and reaction times were also obtained. Noise affected all measures of behavioral frequency discrimination significantly. Except N1, all ERP components in the standard and difference waveforms decreased significantly in amplitude and increased in latency to the same degree in all three subject groups, arguing against a specific age-related sensitivity to the effects of contralateral background noise. For N1 amplitude, the effect of noise was different in the three subject groups, with a complex interaction of age, hearing loss, and attention. Behavioral frequency discrimination was not affected by age but deteriorated significantly in the elderly subjects with hearing loss. In the electrophysiological
\end{abstract}

Correspondence to: Sibylle Bertoli $\cdot$ HNO-Klinik $\cdot$ Universitätsspital • Petersgraben 4, CH-4031, Basel, Switzerland. Telephone: (41) 61265-2042; fax: (41) 61-265-3883; email: sbertoli@uhbs.ch test, age-related changes occurred at various levels. The most prominent finding in the response to the standard stimuli was a sustained negativity (N2) following P2 in the young subjects that was absent in the elderly, possibly indicating a deficit in the inhibition of irrelevant information processing. In the attended difference waveform, significantly larger $\mathrm{N} 2 \mathrm{~b}$ and smaller P3b amplitudes and longer N2b and P3b latencies were observed in the elderly indicating different processing strategies. The pronounced agerelated changes in the later cognitive components suggest that the discrimination of difficult contrasts, although behaviorally maintained, becomes more effortful in the elderly.

Keywords: auditory evoked potentials, mismatch negativity, psychoacoustics, frequency discrimination, distracting cafeteria noise, presbycusis

\section{INTRODUCTION}

Difficulty in understanding speech is a common complaint of elderly persons, especially in adverse listening conditions (Committee on Hearing 1988). There is increasing evidence that peripheral, central auditory, and cognitive factors are involved, although the relative contributions and interactions among these factors have not been fully delineated (Frisina and Frisina 1997). Speech perception in noise requires the ability to focus on relevant information (speech) while inhibiting the processing of irrelevant information (background noise). This selective attention process is impaired by the aging process in 
the visual, somatosensory, and auditory modalities (Hasher and Zacks 1988; Barr and Giambra 1990; McDowd and Filion 1992; Chao and Knight 1997; Friedman et al. 1998). Some studies have suggested a decline in the earlier sensory-perceptual processing stages, whereas others have pointed to the later attentional mechanisms involved in selective attention (for a review, see Plude et al. 1994).

Both behavioral and electrophysiological measures have been used to investigate age-related changes in auditory processing and discrimination. Psychoacoustic measures provide useful information about a listener's auditory perception of a sound. However, performance in such experiments inevitably reflects a conscious attentional process and therefore does not allow conclusions about the level or localization of a deficit nor about how a sound is processed when it is outside the focus of the listener's attention. Auditory event-related potentials (ERPs) may be more suited to determine the stages of central auditory discrimination processes compromised by aging and by hearing loss. They provide excellent temporal resolution of stimulus analysis and allow assessment of the various levels of auditory discrimination, from the earlier sensory perceptual to the later cognitive levels. In addition, ERPs can be recorded with or without the subject's attention, yielding information from different attentional states. Surprisingly, although the impact of background noise on speech understanding in the elderly is a well-known phenomenon, studies using objective methods, such as ERPs, to investigate the underlying mechanisms are lacking. Various ERP studies have investigated the effects of either age, hearing loss, or noise on auditory perception, but studies considering all three factors together are missing.

Event-related potential studies investigating agerelated changes have reported decreasing amplitudes and increasing latencies with increasing age for the earlier sensory-perceptual potentials $\mathrm{P} 1, \mathrm{~N} 1$, and P2, for the preattentive automatic mismatch negativity (MMN) and the later cognitive components N2b and P3b or P300 (e.g., Picton et al. 1984; Ford and Pfefferbaum 1991; Czigler et al. 1992; Woods 1992; Iragui et al. 1993; Karayanidis et al. 1995; Anderer et al. 1996; Polich 1996; Amenedo and Diaz 1998a; Gaeta et al. 1998; Alain and Woods 1999; Pekkonen 2000). These changes seem to occur more consistently in the endogenous, or cognitive, stages of information processing, but less in the exogenous, or sensory-perceptual stages. A few studies have investigated the effect of hearing loss on ERPs yielding equivocal results that may be explained by differences in the subjects' age and degree of hearing loss and the type of stimuli used (Polen 1984; Wall et al. 1991; Oates et al. 2002; Tremblay et al. 2003, 2004).
In contrast, the various studies addressing the effect of background noise on ERPs reported consistently decreased amplitudes and increased latencies comprising all ERPs independent of the type of noise and signal-to-noise $(\mathrm{S} / \mathrm{N})$ ratio (Seidel et al. 1992; Salo et al. 1995; Whiting et al. 1998; Martin et al. 1999; Cunningham et al. 2001; Muller-Gass et al. 2001; Novitski et al. 2001; Salisbury et al. 2002; Wible et al. 2002; Hayes et al. 2003). A specific age-related sensitivity to noise with significantly more decreased $\mathrm{N} 1$ and P2 amplitudes in elderly listeners has also been reported (Cranford and Martin 1991; Hymel et al. 1998; Fisher et al. 2000).

The purpose of the current study was to investigate the effects of age, age-related hearing loss, and a distracting noise on auditory frequency discrimination in young and elderly listeners. Event-related potentials and behavioral measures were used because despite the limitations of psychoacoustic tests, it is important to determine how ERP waveforms are related to behavioral performance. The electrophysiological testing included both unattended and attended conditions to obtain a comprehensive set of ERP components from the earlier sensory-perceptive (P1-N1-P2 complex), preattentive automatic $(\mathrm{MMN})$, and later cognitive attention-related levels of processing (N2b, P3b). Small frequency changes were used as a paradigm in both tests because they are relevant to speech perception. Furthermore, the effects of age on the discriminative potentials MMN, $\mathrm{N} 2 \mathrm{~b}$, and P3b have been shown to be more evident when tested with small stimulus contrasts (Gaeta et al. 1998; Bertoli et al. 2002). A contralateral cafeteria noise was chosen as a distractor because it represents a more realistic daily listening situation than a continuous unmodulated noise. A speech perception in noise (SPIN) test was administered to obtain information about speech understanding in a realistic everyday listening situation. The combination of electrophysiological and behavioral measures, as well as the investigation of the three factors, i.e., age, age-related hearing loss, and distracting noise, within the same study could provide a more comprehensive understanding of presbycusis.

\section{METHODS}

\section{Participants and screening procedures}

Ten young normal-hearing subjects $(\mathrm{YNH}$; mean age $=$ 26.2 years, range 20-38 years; five men), 10 elderly subjects with normal hearing for their age (ENH; mean age $=67.5$ years, range $61-81$ years; six men), and 10 elderly hearing-impaired subjects (EHI; mean age $=72.8$ years, range $67-79$ years; six men) participated. The right ear of each subject was used 
for testing. The mean pure-tone audiograms of the three groups for the right ear are depicted in Figure 1. Pure-tone air-conduction thresholds for the young subjects were $\leq 20 \mathrm{~dB}$ HL from 0.25 to $8 \mathrm{kHz}$, and for the relatively normal-hearing elderly subjects, $\leq 20 \mathrm{~dB}$ HL from 0.25 to $3 \mathrm{kHz}$ and elevated above $3 \mathrm{kHz}$. The elderly hearing-impaired subjects had a mild to moderate high-frequency sensorineural hearing loss with a pure-tone average (PTA at $0.5,1$, and $2 \mathrm{kHz})<50 \mathrm{~dB} \mathrm{HL}$. At $1 \mathrm{kHz}$, there was no significant difference in the hearing thresholds between the $\mathrm{YNH}$ and ENH groups $(p>0.6)$, whereas EHI subjects had significantly higher thresholds compared with those of the two normal-hearing groups $(p<0.0001)$. For all subjects, the difference between left and right ears in the frequency range from 0.25 to $3 \mathrm{kHz}$ did not exceed $15 \mathrm{~dB}$. Conductive hearing loss was ruled out by otoscopy and acoustic immittance testing. All participants had a negative history of persistent tinnitus, head trauma, and neurologic and psychiatric disorders. In addition, elderly subjects were screened for mild cognitive impairment and dementia using a German version of the neuropsychological assessment battery of the Consortium to Establish a Registry for Alzheimer's Disease (CERAD-NAB) (Welsh et al. 1994). This test has been recently introduced as a standard screening instrument for dementia in Germany, Switzerland, and Austria (Thalmann et al. 2000). Normative values demographically adjusted for gender, age, and education are available. All elderly subjects passed the screening assessment.

The young subjects were mainly recruited from among local university students and the elderly from

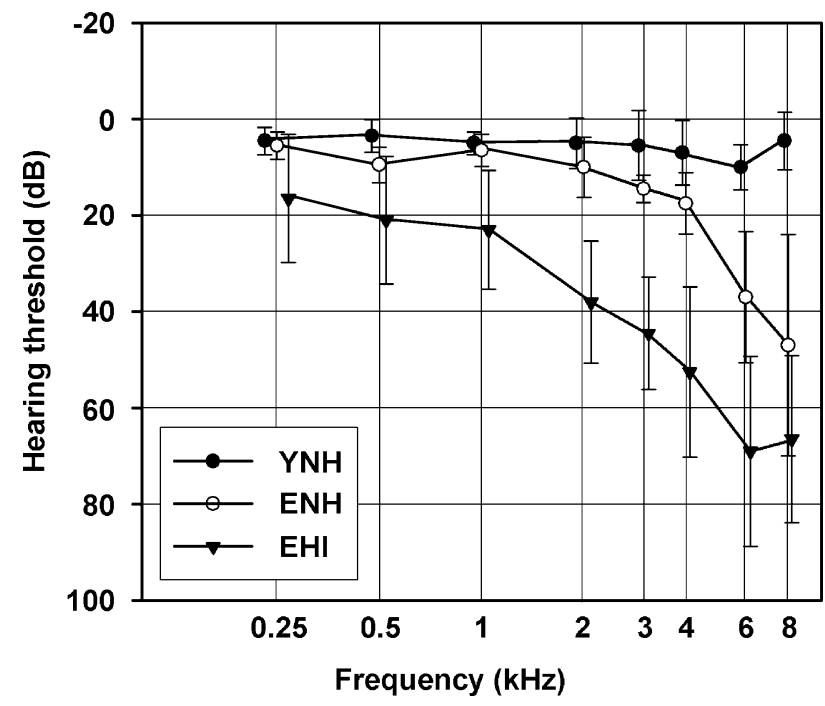

FIG. 1. Mean pure-tone audiograms $( \pm 1 \mathrm{SD})$ for the young normalhearing $(\mathrm{YNH})$, elderly normal-hearing $(\mathrm{ENH})$, and elderly hearingimpaired (EHI) subject groups. an institution called the "senior university." Prior to testing, written informed consent was obtained from all subjects.

\section{SPIN test}

A modified German adaptation of the SPIN test was administered (Kalikow and Stevens 1977; Tschopp and Züst 1994). The test material consists of short sentences presented in a constant background noise of $70 \mathrm{~dB}$ SPL. The listener is asked to repeat the final word of the sentence. This word is always monosyllabic and may have either high predictability (HP) or low predictability (LP) from the preceding context of the sentence. An adaptive test procedure is used increasing or decreasing the speech level by $2 \mathrm{~dB}$, according to whether the final word is recognized or not. The $\mathrm{S} / \mathrm{N}$ ratio for which $50 \%$ of the final words are identified correctly is determined. For LP sentences, this $\mathrm{S} / \mathrm{N}$ ratio is about $-1 \mathrm{~dB}$ for young normalhearing subjects. Two LP lists of the SPIN test were presented monaurally to the right ear, and the mean $\mathrm{S} / \mathrm{N}$ ratios were calculated.

\section{Stimuli}

For both psychoacoustic and electrophysiological tests, pure tones were used. The standard stimuli were $1000-\mathrm{Hz}$ pure tones. To elicit ERPs, three deviant stimuli differing by 64,32 , and $16 \mathrm{~Hz}$ from the standard were created. All stimuli had $10-\mathrm{ms}$ rise/ fall times and a steady-state portion of $200 \mathrm{~ms}$ and were presented at $70 \mathrm{~dB}$ SPL through an ER3 insert earphone.

All tests were performed under two test conditions: in quiet and with the presentation of a distracting contralateral background noise. For this purpose, a file containing digitally recorded speech babble was downloaded from the Internet (http:// spib.rice.edu/spib/data/signals/noise/babble.html; copyrights TNO, Soesterberg, The Netherlands). The source of this babble was 100 people speaking in a canteen. The file was copied to a compact disc with a 10-fold loop with a total duration of the signal of almost $40 \mathrm{~min}$. The noise was presented at the level corresponding to the long-term average of $70 \mathrm{~dB}$ SPL. Pure-tone stimuli were presented to the right ear and the noise to the left ear through ER3 insert earphones with a $\mathrm{S} / \mathrm{N}$ ratio of $0 \mathrm{~dB}$.

\section{Psychoacoustic procedure}

The psychoacoustic procedure was replicated from a previous study by Moore and Peters (1992). An adaptive three-interval, three-alternative forcedchoice procedure with visual feedback was used to 
determine frequency discrimination thresholds for a $1000-\mathrm{Hz}$ sinusoid. A higher frequency occurred randomly in one of the intervals, whereas the frequency of the other two was $1000 \mathrm{~Hz}$. The interstimulus interval was $300 \mathrm{~ms}$. A three-down/ one-up procedure was used to estimate the discrimination threshold yielding a $79.4 \%$ performance level. The initial signal frequency was set at 1040 $\mathrm{Hz}$. After three consecutive correct responses, the frequency difference was decreased by a factor of 1.4. After one incorrect response, the difference was increased by the same factor. Each run was terminated after 12 reversals or after a maximum of 80 trials. The frequency discrimination thresholds (delta $f$ ) were estimated from the average of the last nine reversals.

Prior to data collection, each subject had one or more practice runs for each test condition. Consecutively, at least three runs with consistent threshold estimates were performed for the quiet and the noise condition. Runs were not accepted when the standard deviation was greater than the mean threshold value. The final frequency discrimination thresholds were determined by averaging the results from the three most consistent runs. Psychoacoustic testing was completed with all subjects before the electrophysiological testing.

\section{Electrophysiological procedure}

An oddball paradigm was used to elicit ERPs. There were three deviant stimuli with frequencies of 1064, 1032, and $1016 \mathrm{~Hz}$. The lowest of these frequencies was slightly above the mean frequency discrimination thresholds obtained in the psychoacoustic task performed before the electrophysiological testing. It has been shown that a $1016-\mathrm{Hz}$ deviant is the smallest frequency contrast that still elicits an MMN in young normal-hearing subjects (Sams et al. 1985).

Stimuli were presented with an interstimulus interval (offset-to-onset) of $500 \mathrm{~ms}$ in blocks of 500 stimuli. The deviants/targets occurred among the standard stimuli at a probability of 0.15 in a pseudorandomized sequence, with at least three standard stimuli preceding each deviant. Each deviant type (either 1064, 1032, or $1016 \mathrm{~Hz}$ ) was presented in two blocks, which were run during separate recording sessions. Stimuli were presented with and without contralateral noise under both passive and active listening conditions yielding four different test conditions: unattended quiet, unattended noise, attended quiet, and attended noise.

Recordings were conducted in a sound-treated and electrically shielded room. There were four recording sessions, each containing six runs. In total, 24 runs were presented to each subject. During the first two sessions, subjects were instructed to ignore the sounds and to concentrate on reading a text of their own choice. In the two following sessions, subjects were asked to attend to the sounds and to press a button on a response box when they heard a deviant stimulus. Measures of reaction time (RT) and number of hits and false alarms were obtained by the STIM software of the Neuroscan system. A hit occurred when the subject responded to a deviant within a response window of 100-1000 ms after stimulus onset. The $d^{\prime}$ detectability indexes were calculated for each of the three deviants for the quiet and noise conditions (Swets 1964).

\section{EEG recording}

The EEG was recorded using a Neuroscan QuickTrace system and disposable surface silver electrodes at Fz, Cz, Pz, left mastoid (LM), right mastoid (RM) according to the International $10 / 20$ system, and at L1 (midway between $\mathrm{Fz}$ and $\mathrm{LM}$ ) and R1 (midway between Fz and RM). An electrode placed at the tip of the nose served as the reference and a forehead electrode as ground. Two electrodes placed above and below the left eye were used to monitor for vertical eye movements and eye blinks. Impedance was kept below $5 \mathrm{k} \Omega$ and was controlled during the recording sessions.

The EEG (band pass $0.05-100 \mathrm{~Hz}$ ) was recorded continuously at a sampling rate of $500 \mathrm{~Hz}$ and stored on a disc for off-line averaging. An ocular artifact reduction algorithm was used to reduce contamination by eye movements. EEG epochs of $700 \mathrm{~ms}$, starting $100 \mathrm{~ms}$ prior to stimulus onset, were obtained, baseline corrected ( $-100-0 \mathrm{~ms})$, and averaged separately for the standard and deviant/target stimuli. Epochs containing artifacts exceeding $\pm 100 \mu \mathrm{V}$ were rejected from averaging. Event-related potential waves were digitally band-pass filtered at $0.1-30 \mathrm{~Hz}$.

\section{Electrophysiological data analyses}

For each subject and each of the four conditions, averages were created for the standards and for each of the three deviants. Replications were averaged together for each condition and stimulus type. Individual difference waveforms were obtained by subtracting the response to the standard stimulus from the response to the deviant stimulus. Grand mean average waveforms were calculated for each subject group and deviant type from the four test conditions.

Individual mean standard waveforms were created for each of the four conditions by averaging the three standard responses together. P1, N1, and P2 peak 
amplitudes and latencies were measured in the responses to the standard stimuli at $\mathrm{Cz}$. The latency windows determined based on the respective grand average waveforms were $30-80 \mathrm{~ms}$ for $\mathrm{P} 1,60-130 \mathrm{~ms}$ for N1, and 120-270 ms for P2. To analyze the negative deflection following $\mathrm{P} 2$, which will be labeled subsequently N2, two mean amplitude voltages were measured in the standard waveforms for the 200-350 and the 350-500 ms latency ranges $\left(\mathrm{N} 2_{\text {early }}\right.$ and $\mathrm{N}_{2}$ late, respectively). The decision to calculate two mean amplitudes was based on a visual inspection of the four standard waveforms revealing different effects of noise and attention on the two latency ranges between the subject groups.

Mismatch negativity measurements were performed on the difference waveforms of the unattended condition. First, for each subject group, deviant type, and condition, MMN peak latencies were identified in the grand mean difference waveforms considering both the response at $\mathrm{Fz}$ and the inversion at the mastoids. Individual MMN mean amplitudes were then measured at Fz in the 50-ms latency window surrounding the mean MMN peak latency (25 ms on either side). At the group level, a point-bypoint one-tailed paired $t$ test was performed on the difference waves to determine the time period during which the MMN differed significantly from zero. Based on the method described by Guthrie and Buchwald (1991) for evaluating the statistical significance of difference potentials, a continuous significant interval of at least 12 sampling points $(24 \mathrm{~ms})$ was considered to be sufficient to determine the presence of MMN at the 5\% level. A positivity following the MMN was also analyzed. First, the peak latencies of the positive wave were determined in the grand mean difference waveforms of the young subjects for each deviant type and noise condition. Then the individual mean voltages were calculated at Fz for a 50-ms time window around the peak latency.

N2b and P3b peak amplitudes and latencies were measured in the difference waves of the attended condition. N2b was defined as the largest negativity occurring between 190 and $380 \mathrm{~ms}$ at $\mathrm{Cz}$ and $\mathrm{P} 3 \mathrm{~b}$ as the largest positivity between 290 and $560 \mathrm{~ms}$ at Pz.

Electrode sites for each peak were selected because amplitudes were largest at those sites. The decision to restrict data analysis to one electrode was based on a visual inspection of the scalp distribution of ERPs showing that the results were not specific to the selected electrodes but consistent with adjacent electrodes. Furthermore, preliminary repeated-measures analyses of variance (ANOVAs), including electrode sites $\mathrm{Fz}, \mathrm{Cz}, \mathrm{Pz}, \mathrm{L} 1$, and $\mathrm{R} 1$, had yielded the same main effects as ANOVAs performed for a single electrode. Event-related potential amplitudes and latencies as well as psychoacoustic and behavioral measures were analyzed using repeated-measures ANOVAs with factors subject group (YNH, ENH, EHI), frequency deviance (1064, 1032, $1016 \mathrm{~Hz})$, noise condition (quiet, noise), and attention condition (unattended, attended). Effects of attention will be reported elsewhere in more detail, the focus of the present report being the effects of age, hearing loss, and noise. Fisher's PLSD post hoc measures were performed to investigate significant main effects or interactions.

\section{RESULTS}

\section{SPIN test}

The average $\mathrm{S} / \mathrm{N}$ ratio of the SPIN tests was $-0.4 \mathrm{~dB}$ (SD $\pm 1.6 \mathrm{~dB}$, range $-2.4-2.6 \mathrm{~dB}$ ) for the $\mathrm{YNH},-1.4$ $\mathrm{dB}(\mathrm{SD} \pm 1.6 \mathrm{~dB}$, range $-4.0-1.4 \mathrm{~dB}$ ) for the $\mathrm{ENH}$, and $6.4 \mathrm{~dB}(\mathrm{SD} \pm 7.0 \mathrm{~dB}$, range $1.2-20.0 \mathrm{~dB}$ ) for the EHI subjects. The two normal-hearing groups had significantly smaller $\mathrm{S} / \mathrm{N}$ ratios compared with those of the EHI group ( $p$ values $<0.002$ ). No significant difference was found between $\mathrm{YNH}$ and ENH subjects $(p>0.5)$.

\section{Psychoacoustic frequency discrimination task}

The mean frequency discrimination thresholds of the three subject groups for the quiet and noise conditions are depicted in Figure 2. The mean frequency discrimination thresholds in quiet for the $1000-\mathrm{Hz}$ pure tone were $4.5 \mathrm{~Hz}(\mathrm{SD} \pm 1.8 \mathrm{~Hz}$ ) for the $\mathrm{YNH}, 6.6$ $\mathrm{Hz}(\mathrm{SD} \pm 2.7 \mathrm{~Hz})$ for the $\mathrm{ENH}$, and $9.4 \mathrm{~Hz}(\mathrm{SD} \pm 6.2$ $\mathrm{Hz})$ for the EHI subjects. When cafeteria noise was presented contralaterally, discrimination thresholds increased in all three groups compared with those obtained in the quiet condition: $\mathrm{YNH}$ by $1.5 \mathrm{~Hz}$ (SD $\pm 1.5 \mathrm{~Hz}$ ), ENH by $0.7 \mathrm{~Hz}(\mathrm{SD} \pm 2.3 \mathrm{~Hz})$, and EHI by $2.8 \mathrm{~Hz}(\mathrm{SD} \pm 8.8 \mathrm{~Hz})$. A two-way repeated-measures

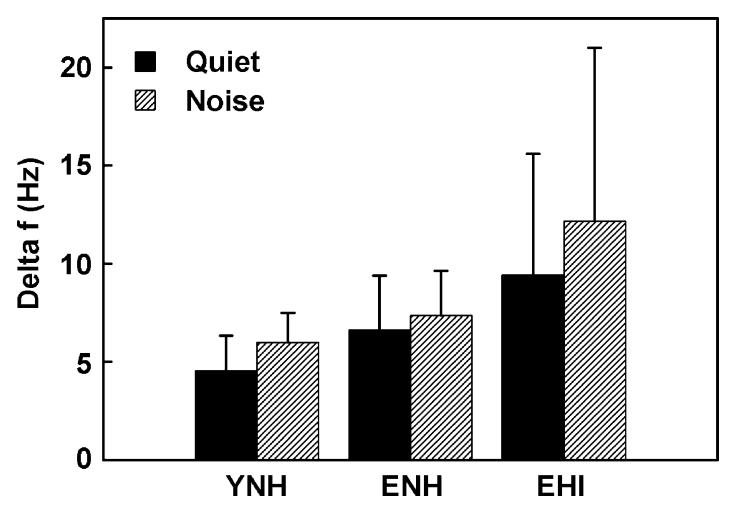

FIG. 2. Mean frequency discrimination thresholds $( \pm 1 \mathrm{SD})$ of the three subject groups for the quiet and noise conditions. 
TABLE 1

$F$ values of repeated-measures ANOVAs for the psychoacoustic and behavioral data

\begin{tabular}{lcccc}
\hline Factor & $d f$ & Delta $f$ & $d^{\prime}$ detectability index & Reaction time \\
\hline Group (G) & 2,27 & $3.75^{*}$ & $5.05^{*}$ & 0.79 \\
Noise (N) & 1,27 & $18.49^{* * *}$ & $18.53^{* * *}$ & $22.79^{* * *}$ \\
Deviance (D) & 2,54 & & $51.12^{* * *}$ & $167.34^{* * *}$ \\
$\mathrm{G} \times \mathrm{N}$ & 2,27 & 2.44 & 1.36 & 2.11 \\
$\mathrm{G} \times \mathrm{D}$ & 4,54 & & 1.93 & 0.93 \\
$\mathrm{~N} \times \mathrm{D}$ & 2,54 & & $6.88^{* *}$ & $5.7^{* *}$ \\
\hline
\end{tabular}

${ }^{*} p<0.05$.

$* * p<0.01$.

$* * * p<0.001$.

ANOVA revealed a significant main effect for subject group (see Table 1). Post hoc tests showed that the YNH subjects performed significantly better than those of the EHI group $(p<0.02)$. No significant differences were found between $\mathrm{YNH}$ and $\mathrm{ENH}(p>$ $0.4)$ and between ENH and EHI groups $(p>0.07)$. Thus it appears that age-related hearing loss, but not age by itself, affects frequency discrimination. There was also a significant main effect of noise condition, but no significant subject group and noise condition interaction suggesting a similar effect of background noise for the three groups. Variability of discrimination thresholds was considerably larger in the elderly subjects with hearing loss due to three subjects with increased frequency discrimination thresholds compared with the group mean.

Behavioral data from the active condition of the electrophysiological tests

$\boldsymbol{d}^{\prime}$ detectability indexes. Figure 3 a displays the $d^{\prime}$ detectability indexes for the 1016-, 1032-, and $1064-\mathrm{Hz}$ targets obtained from the attended condition of the electrophysiological testing. In all three subject groups, $d^{\prime}$ scores increased with increasing frequency contrasts and decreased with the presentation of contralateral background noise. This effect was largest for the smallest frequency contrast. The effect of noise was similar for the three subject groups. The results of a repeated-measures ANOVA indicated a significant main effect for subject group, noise condition, and stimulus deviance (Table 1). There was also a significant interaction of noise condition and stimulus deviance, indicating that the effect of background noise was larger for the smaller frequency contrasts. Post hoc analyses of the group effect showed a significant difference of $d^{\prime}$ between the ENH and EHI subjects $(p<0.004)$. It should be noted that the ENH subjects had higher $d^{\prime}$ detectability indexes for all three targets in quiet and in noise compared with those of the $\mathrm{YNH}$ group, although this difference did not reach significance $(p>0.1)$.
There was no significant interaction of subject group and noise condition indicating a similar effect of contralateral cafeteria noise for the three groups.

Reaction times. Figure $3 \mathrm{~b}$ displays the reaction times for the 1016-, 1032-, and 1064-Hz targets from the quiet and noise conditions. There was no significant subject group effect on RTs. RTs increased significantly with the presentation of contralateral cafeteria
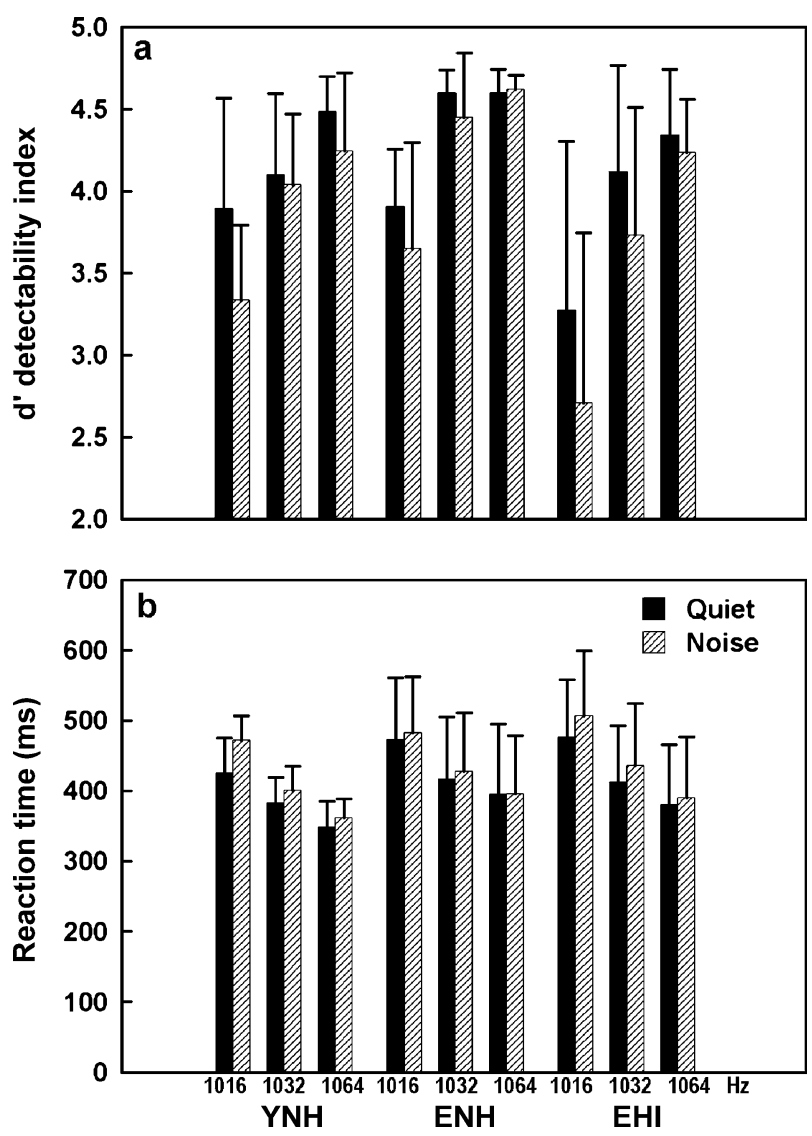

FIG. 3. Mean $d^{\prime}$ detectability indexes ( \pm 1 SD; upper panel) and reaction times ( \pm 1 SD; lower panel) for the 1016-, 1032-, and 1064$\mathrm{Hz}$ targets in quiet and in noise obtained from the attended conditions of the electrophysiological testing for the three subject groups. 
noise and with decreasing frequency contrasts. Again, the effect of noise was similar for the three subject groups.

In summary, results of the psychoacoustic test as well as the behavioral data ( $\left.d^{\prime}, \mathrm{RT}\right)$ obtained during the active ERP conditions did not reveal a significant decline in frequency discrimination with age alone. However, hearing loss affected frequency discrimination significantly. Furthermore, the effect of a contralateral background noise was similar for the three subject groups, indicating a lack of an age-specific decline of behavioral frequency discrimination.

\section{Electrophysiological data}

P1, N1, P2, and N2 in standard waveforms. Figure 4 depicts the grand mean standard waveforms at all eight electrode sites for the unattended quiet condition. Figure 5 displays the grand mean standard waveforms at electrode site $\mathrm{Cz}$ for the four test conditions and the three subject groups. In Figure 6, the responses to the standard stimuli from the quiet and noise conditions are plotted for the three subject groups in the unattended and attended conditions. The P1, N1, and P2 components represent the earlier and mainly sensory-perceptual stages of processing. They are sensitive to changes in the physical characteristics of the stimuli and can be elicited regardless of the subject's attention to the stimuli. P2 was followed by a sustained negativity lasting from about 200 to $500 \mathrm{~ms}\left(\mathrm{~N} 2_{\text {early }}\right.$ and N2 late $)$ in the young subjects in all four conditions. This negativity was not seen in the waveforms of the elderly subjects.

Amplitudes. The results of a three-way repeatedmeasures ANOVA with factors subject group, noise condition, and attention condition performed separately for $\mathrm{P} 1, \mathrm{~N} 1$, and $\mathrm{P} 2$ peak amplitudes and latencies and N2 mean amplitudes are summarized in Table 2.

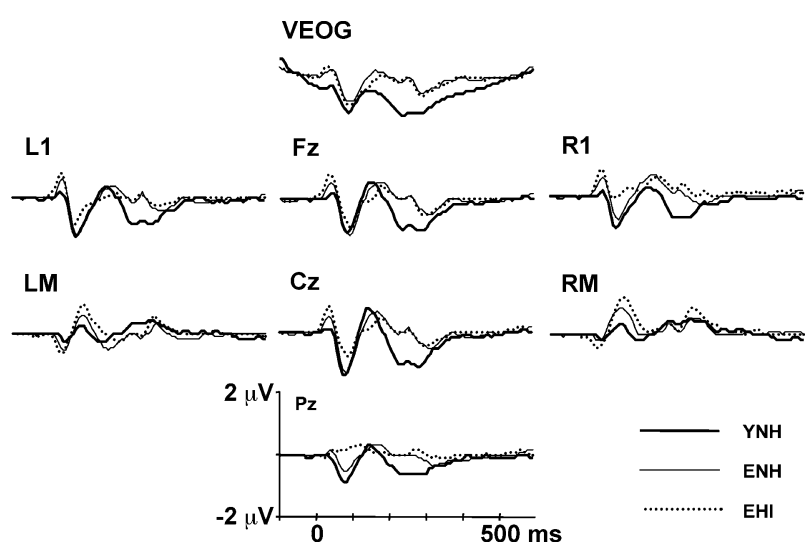

FIG. 4. Grand mean standard waveforms of the three subject groups $(\mathrm{YNH}, \mathrm{ENH}, \mathrm{EHI})$ from the unattended quiet condition at all eight electrode sites.

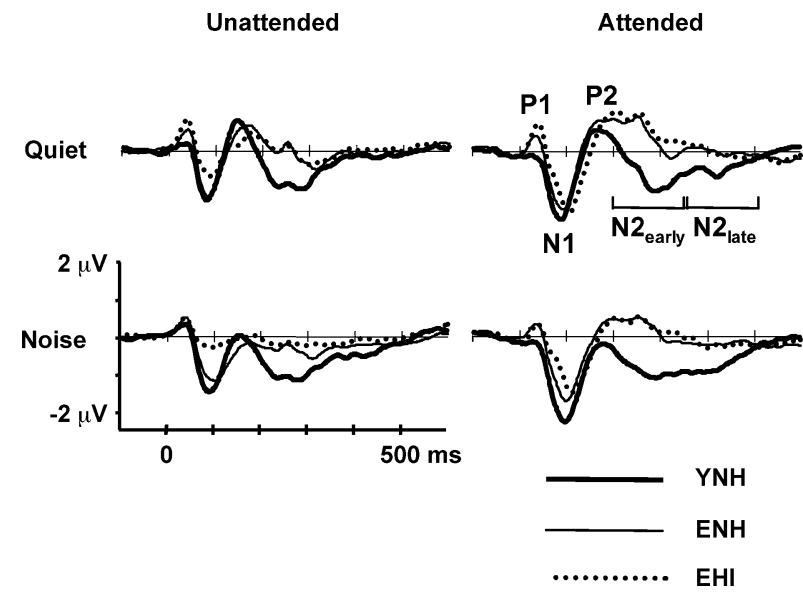

FIG. 5. Grand mean standard waveforms of the young normalhearing $(\mathrm{YNH})$, elderly normal-hearing $(\mathrm{ENH})$, and elderly hearingimpaired (EHI) subjects from the four test conditions (unattended quiet, unattended noise, attended quiet, and attended noise) recorded at electrode site $\mathrm{Cz}$.

P1: There was a significant main effect of subject group, attention, and noise condition. There were no significant interactions with subject group suggesting similar effects of attention and noise in young and elderly subjects. Post hoc analyses indicated that the YNH subjects had significantly smaller P1 amplitudes than the ENH $(p<0.04)$ and EHI groups $(p<0.004)$.

N1: There was a significant main effect of attention for N1. With attention, N1 amplitudes increased. There were no significant main effects of subject group and noise condition, but there was a significant interaction between them indicating a different effect of noise on N1 amplitude in the subject groups. Post hoc tests showed that the EHI subjects had significantly smaller N1 amplitudes than those

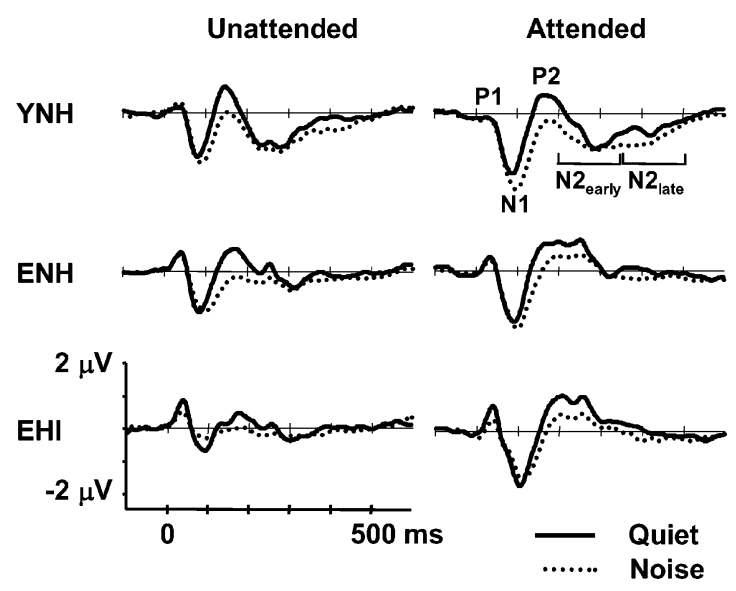

FIG. 6. Grand mean standard waveforms of the three subject groups ( $\mathrm{YNH}, \mathrm{ENH}, \mathrm{EHI})$ and two attention conditions (unattended, attended) as a function of the noise condition (quiet, contralateral cafeteria noise) recorded at electrode site $\mathrm{Cz}$. 
TABLE 2

$F$ values of repeated-measures ANOVAs for the ERP amplitudes and latencies from the standard waveforms

\begin{tabular}{|c|c|c|c|c|c|c|c|c|c|}
\hline \multirow[b]{2}{*}{ Factor } & \multirow[b]{2}{*}{$d f$} & \multicolumn{5}{|c|}{ Amplitudes } & \multicolumn{3}{|c|}{ Latencies } \\
\hline & & $P 1$ & N1 & $P 2$ & $N 2_{\text {early }}$ & $\mathrm{N} 2_{\text {late }}$ & P1 & N1 & $P 2$ \\
\hline Group (G) & 2,27 & $5.46^{*}$ & 1.79 & 0.39 & $9.68^{* * *}$ & $6.64^{* *}$ & 2.10 & 1.41 & $6.16^{* *}$ \\
\hline Noise (N) & 1,27 & $9.46^{* *}$ & 0.06 & $49.43^{* * *}$ & $15.78^{* * *}$ & $23.64 * * *$ & 3.33 & $20.65^{* * *}$ & $9.17^{* *}$ \\
\hline Attention (A) & 1,27 & $11.69^{* *}$ & $29.98 * * *$ & $6.56^{*}$ & $11.32^{* *}$ & $5.61 *$ & $4.59 *$ & $22.16^{* * *}$ & $18.83^{* * *}$ \\
\hline$G \times N$ & 2,27 & 2.80 & $4.11^{*}$ & 0.88 & 0.00 & 0.60 & 0.57 & 0.87 & 1.53 \\
\hline$G \times A$ & 2,27 & 1.33 & 2.22 & 1.92 & 2.48 & $6.13^{* *}$ & 0.02 & 1.07 & 0.62 \\
\hline$N \times A$ & 1,27 & 2.93 & $5.82^{*}$ & 0.01 & 3.27 & 2.69 & 0.59 & 0.01 & $7.61^{*}$ \\
\hline
\end{tabular}

${ }^{*} p<0.05$.

$*^{* *} p<0.01$.

${ }^{* * *} p<0.001$.

seen in the $\mathrm{YNH}$ data in quiet $(p<0.04)$ and in noise $(p<0.0007)$ when the stimuli were unattended. In addition, N1 amplitudes were significantly smaller in the EHI subjects compared with those of the ENH group in the unattended noise condition $(p<0.01)$. Whereas $\mathrm{N} 1$ amplitudes increased in the $\mathrm{YNH}$ subjects when contralateral cafeteria noise was presented, the amplitudes of the responses from the ENH group decreased with noise in the unattended and increased in the attended condition. N1 amplitudes of the EHI subjects decreased with noise in both attention conditions.

Separate ANOVAs for the unattended and attended conditions were also performed. They revealed a significant decrease of $\mathrm{N} 1$ amplitude in the unattended condition in the EHI group compared with the two normal-hearing groups $(p<0.004$ and $p<0.03$, respectively) but not in the attended condition $(p>$ $0.3)$.

P2: P2 amplitudes did not differ between the three subject groups. There was a significant main effect of attention and noise on P2 amplitude. With attention, P2 amplitudes increased. Presence of contralateral cafeteria noise reduced P2 amplitudes in all subject groups, regardless of whether stimuli were ignored or attended to. The degree of this effect was similar for the young and elderly subjects, as there was no signifcant interaction of noise condition with subject group.

N2: A three-way repeated-measures ANOVA yielded a significant main effect of subject group for the early and late portion of N2. Post hoc tests indicated that both the ENH and EHI subjects had significantly smaller N2 mean amplitudes compared with those of the $\mathrm{YNH}$ group ( $\mathrm{N} 2_{\text {early: }}: p<0.002$ and $<0.005$; $\mathrm{N}_{\text {late: }}$ : $p<0.007$ and $<0.003)$. There was also a significant main effect of attention for $\mathrm{N} 2$ early and $\mathrm{N} 2$ late. Furthermore, there was a significant interaction of attention with subject group for $\mathrm{N} 2_{\text {late }}$ indicating that in the young subjects, the negative deflection in- creased when attention was directed to the stimuli, whereas in the elderly subjects, the opposite trend was found. Presentation of contralateral noise increased the early and late portions of the negativity in all three subject groups significantly.

Latencies. No significant effect of subject group on P1 and N1 latencies was found, but both elderly subject groups had significantly increased P2 latencies compared with the young subject group (post hoc: ENH $p<0.04$; EHI $p<0.002$ ). A significant noise effect was found for N1 and P2 latencies, indicating increased latencies in the presence of background noise. There was a significant main effect of attention on P1, N1, and P2 latencies. For P1, latencies decreased, whereas for $\mathrm{N} 1$ and $\mathrm{P} 2$, latencies increased with attention. A significant interaction of attention condition with noise condition for P2 latency suggests that the effect of noise was more pronounced when the stimuli were attended.
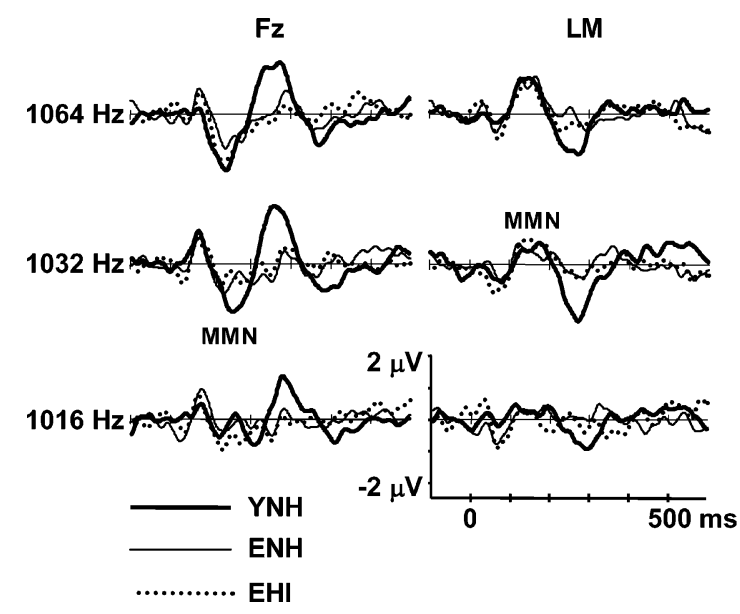

FIG. 7. Grand mean difference waveforms of the unattended quiet condition in response to the 1016-, 1032-, and 1064-Hz deviants at electrode sites Fz and LM for the three subject groups (YNH, ENH, $\mathrm{EHI})$. 

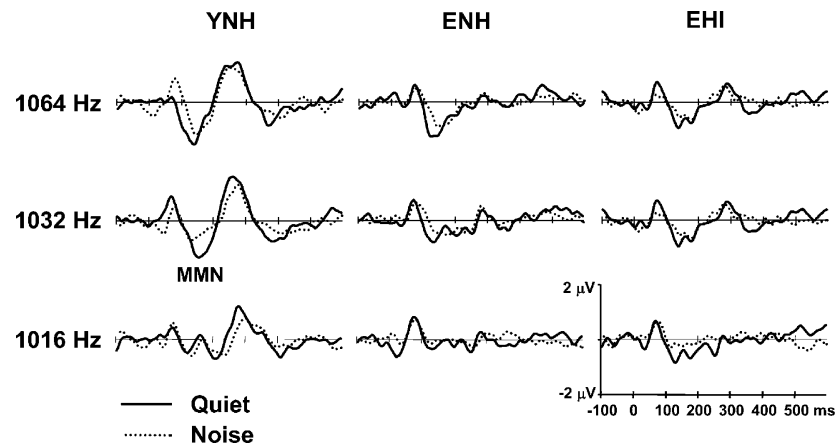

FIG. 8. Grand mean difference waveforms of the unattended condition for the three stimulus deviants and the three subject groups as a function of the noise condition (quiet, contralateral cafeteria noise) at electrode site Fz.

\section{$M M N$ in unattended difference waveforms}

Figure 7 depicts the grand average difference waves of the quiet condition in response to the three frequency contrasts at electrode sites Fz and LM for the three subject groups. In Figure 8, the grand average waveforms of the three subject groups are shown for the test conditions with and without presentation of contralateral cafeteria noise. The MMN indicates whether a rare deviant stimulus occurring occasionally among a series of frequent standard stimuli has been detected. It is considered to be an automatic response that can be elicited in the absence of conscious attention. Mismatch negativities are visible in the difference waveforms of the 1064- and 1032-Hz deviants in all three groups. The MMNs of the YNH subjects, in particular, the response to the $1032-\mathrm{Hz}$ deviant, were larger in amplitude compared with those of the ENH and EHI groups. In the waveforms of the young subjects, the MMN negativity was followed by a large positive difference wave at a latency of 200-350 ms at $\mathrm{Fz}$ and $\mathrm{Cz}$, with inverted polarities at LM and RM. This positivity could be seen for all three frequency contrasts. In the difference waves of the elderly subjects, this positivity was absent.

Table 3 gives an overview of a point-by-point onetailed paired $t$ test performed on the difference waves to determine presence/absence of MMN for the three subject groups and various conditions. Individ- ual MMN mean amplitudes were measured from the difference waves at $\mathrm{Fz}$ within specified latency windows determined on the basis of the grand average waveforms of each subject group and frequency contrast.

A three-way repeated-measures ANOVA was performed on the mean MMN amplitudes (see Table 4). There was a significant main effect of noise condition and stimulus deviance. There was no significant effect of subject group on MMN amplitude and no significant interaction between subject group and noise condition, indicating that the effect of noise on MMN amplitudes was similar for all subjects.

Mismatch negativity peak latencies were measured at the most negative point within the latency window for each condition and stimulus deviance. There was a significant main effect of noise condition and stimulus deviance. No significant effect of subject group was found. Mismatch negativity latencies increased significantly when contralateral cafeteria noise was presented and decreased with increasing frequency contrast between standard and deviant.

Individual mean amplitudes for the positivity following the MMN were measured at $\mathrm{Fz}$ within latency windows based on the grand average waveforms of the young subjects. A three-way repeatedmeasures ANOVA revealed a significant main effect of subject group and a significant interaction between subject group and noise condition (see Table 4). Post hoc tests showed that the young subjects had significantly larger mean positive deflections than both elderly groups ( $p$ values $<0.002$ ).

\section{$\mathrm{N} 2 \mathrm{~b}$ and $\mathrm{P} 3 \mathrm{~b}$ in attended difference waveforms}

Figure 9 displays the difference waveforms at all eight electrode sites of the attended condition for the 1064-Hz target. Figure 10 illustrates the difference waveforms of the attended condition at electrode site $\mathrm{Cz}$ for the three subject groups. Figure 11 depicts the difference waveforms of the attended condition as a function of contralateral cafeteria noise. The components $\mathrm{N} 2 \mathrm{~b}$ and $\mathrm{P} 3 \mathrm{~b}$ occur in response to a deviant stimulus, when the difference has been consciously perceived.

TABLE 3

Presence $(+)$ or absence $(-)$ of MMN as determined by point-by-point one-tailed paired $t$ test

\begin{tabular}{|c|c|c|c|c|c|c|}
\hline \multirow[b]{2}{*}{ Frequency deviance $(\mathrm{Hz})$} & \multicolumn{2}{|c|}{ Young } & \multicolumn{2}{|c|}{ Elderly normal hearing } & \multicolumn{2}{|c|}{ Elderly hearing impaired } \\
\hline & Quiet & Noise & Quiet & Noise & Quiet & Noise \\
\hline 1016 & + & - & - & - & + & - \\
\hline 1032 & + & + & + & - & + & - \\
\hline 1064 & + & + & + & + & + & + \\
\hline
\end{tabular}


TABLE 4

$F$ values of repeated-measures ANOVAs for the ERP amplitudes and latencies from the unattended and attended difference waveforms

\begin{tabular}{|c|c|c|c|c|c|c|c|c|}
\hline \multirow[b]{2}{*}{ Factor } & \multirow[b]{2}{*}{$d f$} & \multicolumn{4}{|c|}{ Amplitudes } & \multicolumn{3}{|c|}{ Latencies } \\
\hline & & $M M N$ & Post-MMN positivity & $N 2 b$ & $P 3 b$ & $M M N$ & $N 2 b$ & $P 3 b$ \\
\hline Group (G) & 2,27 & 2.25 & $10.04^{* * *}$ & $8.15^{* *}$ & $5.65^{* *}$ & 2.45 & $20.23^{* * *}$ & $28.75^{* * *}$ \\
\hline Noise (N) & 1,27 & $8.82 * * *$ & 0.23 & $9.77^{* *}$ & $5.01 *$ & $4.63^{*}$ & $11.55^{* *}$ & $11.25^{* *}$ \\
\hline Deviance (D) & 2,54 & $12.92^{* * *}$ & 0.35 & $15.63^{* * *}$ & $11.49 * * *$ & $56.75^{* * *}$ & $76.68^{* * *}$ & $35.10^{* * *}$ \\
\hline $\mathrm{G} \times \mathrm{N}$ & 2,27 & 0.15 & $3.43^{*}$ & $4.02 *$ & 2.10 & 0.70 & 0.93 & 1.13 \\
\hline$G \times D$ & 4,54 & 1.52 & 2.04 & $9.52^{* * *}$ & $2.73^{*}$ & $3.53^{*}$ & 0.94 & 0.13 \\
\hline $\mathrm{N} \times \mathrm{D}$ & 2,54 & 0.14 & 0.02 & $4.74^{*}$ & 1.05 & 0.32 & 1.07 & $5.12 * *$ \\
\hline
\end{tabular}

${ }^{*} p<0.05$

$* * p<0.01$.

${ }^{* * *} p<0.001$

Amplitudes. Separate repeated-measures ANOVAs were performed on N2b and P3b peak amplitudes and latencies (see Table 4). For N2b amplitude, significant main effects were found for subject group, noise condition, and stimulus deviance. Post hoc tests revealed that the $\mathrm{YNH}$ subjects had significantly smaller N2b amplitudes than the ENH $(p<0.002)$ and EHI groups $(p<0.003)$. There was an interaction of noise condition with subject group indicating that N2b amplitudes were reduced with noise in both elderly subject groups $(p<0.05$ and $p<0.004$, respectively), but not in the young group $(p>0.8)$. There was also an interaction of stimulus deviance with subject group. In the elderly, N2b amplitudes increased with increasing stimulus deviance, whereas in the young subjects, N2b amplitudes tended to decrease. An interaction of noise condition and stimulus deviance indicated that the effect of noise was different for the three frequency contrasts.

Similar results were found for the P3b amplitude with main effects of subject group, noise condition, and stimulus deviance. That is, P3b amplitudes were

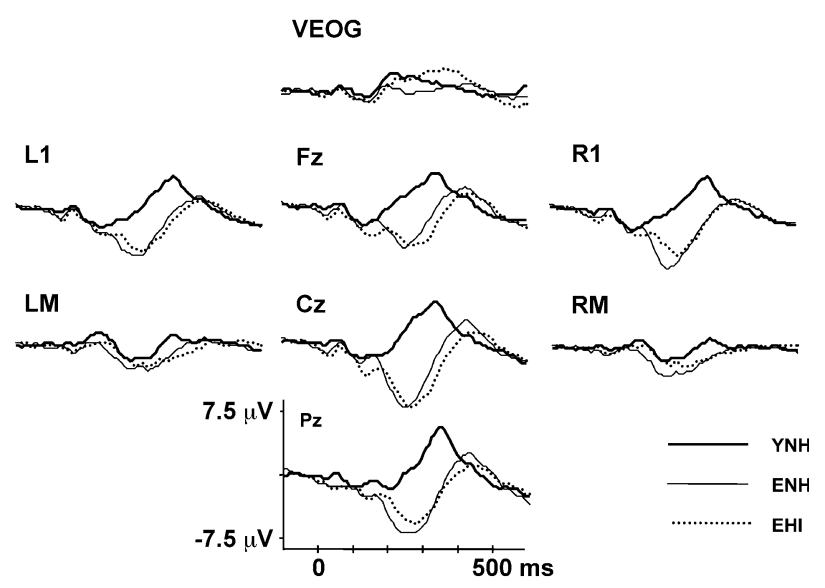

FIG. 9. Grand mean difference waveforms of the attended condition in response to the $1064-\mathrm{Hz}$ target at all eight electrode sites for the three subject groups (YNH, ENH, EHI). significantly reduced in both the ENH and EHI subjects as compared with those of the YNH group $(p<$ 0.04 and $p<0.003$, respectively). Noise reduced P3b amplitudes significantly in all three subject groups. A significant interaction of subject group and stimulus deviance indicated that both the $\mathrm{YNH}$ and $\mathrm{ENH}$ subjects had increasing P3b amplitudes with increasing stimulus contrast, whereas in the EHI data, the degree of deviance had no effect on P3b amplitude.

Latencies. There was a significant main effect of subject group on both N2b and P3b latency. According to post hoc tests, the responses of the ENH and EHI subjects were delayed compared with those of the YNH group (N2b: $p<0.0001$ and $p<0.0004$, respectively; P3b: $p<0.0001$ for both elderly groups). In addition, the EHI subjects had significantly longer

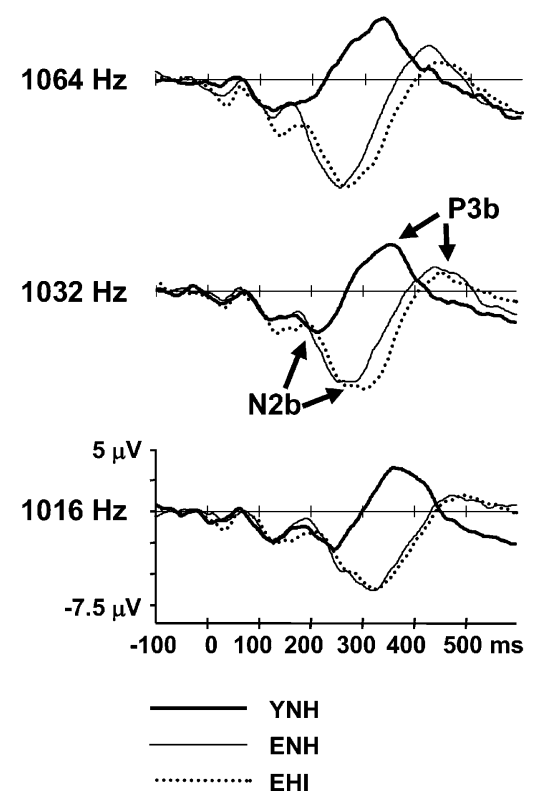

FIG. 10. Grand mean difference waveforms of the attended condition in response to the 1016-, 1032-, and 1064-Hz targets at electrode site $\mathrm{Cz}$ for the three subject groups ( $\mathrm{YNH}, \mathrm{ENH}, \mathrm{EHI})$. 


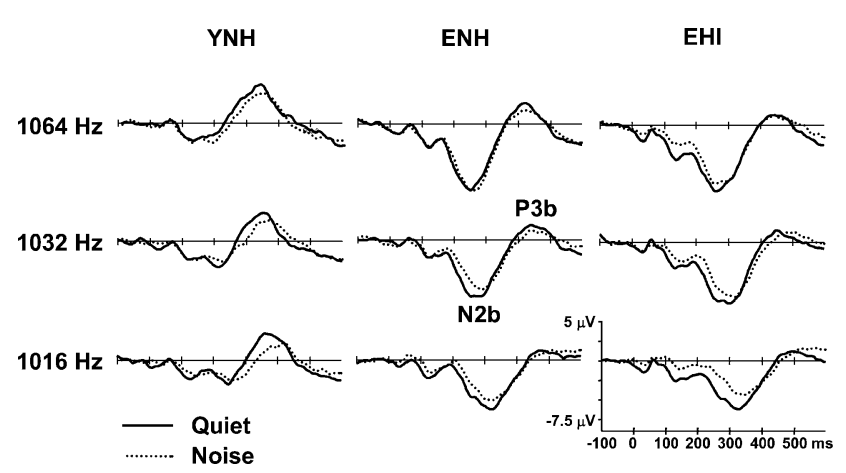

FIG. 11. Grand mean difference waveforms of the attended condition for the three stimulus targets and the three subject groups as a function of the noise condition (quiet, contralateral cafeteria noise) at electrode site $\mathrm{Cz}$.

N2b latencies compared with the ENH group $(p<$ $0.05)$. P3b latencies did not differ significantly between the two elderly subject groups $(p>0.1)$. The presentation of contralateral cafeteria noise further delayed the latencies of N2b and P3b. This effect was similar for all three subject groups, as there was no interaction of subject group and noise condition.

\section{Correlation between electrophysiological and behavioral measures}

The association between ERP measures (MMN, N2b, and P3b amplitudes and latencies) and behavioral measures ( $d^{\prime}, \mathrm{RT}$, delta $f, \mathrm{~S} / \mathrm{N}$ ratio) of auditory discrimination performance was investigated using Pearson's product-moment correlations. To reduce the number of correlation coefficients, data of the three deviance levels $(1064,1032$, and $1016 \mathrm{~Hz}$ ) from each condition were averaged together. The correlation coefficients are displayed in Table 5. Most correlations (37 out of 48) were not significant. The most consistent correlations with behavioral mea- sures were found for N2b latency (five out of eight) and, to a minor extent, for P3b latency (three out of eight). For the amplitude measures, only three out of 24 correlations were significant (MMN, P3b). With one exception, all significant correlations were obtained for the behavioral indexes derived from adaptive test procedures (delta $f, \mathrm{~S} / \mathrm{N}$ ratio), but not for the behavioral indexes from ERP testing.

\section{DISCUSSION}

\section{Summary of main findings}

Given the known age-related impairment of selective attention processes, some age-specific effect of a distracting contralateral noise on auditory processing might have been expected. However, with the exception of the early ERP component N1, noise did not affect auditory processing differently in young and elderly listeners, even in those elderly subjects with presbycusis.

Another important finding was that there were pronounced differences in the morphology of ERPs (mainly the standard N2 and the later components N2b and P3b) between young and elderly subjects, even in those elderly subjects with normal hearing at the test frequencies. In contrast, the behavioral test results were similar for the young and elderly normal hearing subjects. This dissociation between behavioral and physiological data might suggest that the same auditory input is processed differently with increasing age to maintain behavioral performance.

Age-related hearing loss affected behavioral frequency discrimination and speech perception in noise (as indicated by the increased $\mathrm{S} / \mathrm{N}$ ratio in the SPIN test) significantly. In contrast, there were only few differences ( 11 amplitude decrease, N2b latency increase) in the ERPs between elderly subjects with or without audiometric presbycusis indicating that a mild-to-moderate hearing loss does not

TABLE 5

Correlation coefficients between ERP parameters (MMN, N2b, and P3b amplitudes and latencies) and behavioral measures $\left(d^{\prime}, \mathrm{RT}\right.$, delta $f, \mathrm{~S} / \mathrm{N}$ ratio)

\begin{tabular}{|c|c|c|c|c|c|c|c|c|c|c|c|c|}
\hline & \multicolumn{6}{|c|}{ Amplitudes } & \multicolumn{6}{|c|}{ Latencies } \\
\hline & $\begin{array}{c}\text { MMN } \\
\text { quiet }\end{array}$ & $\begin{array}{l}\text { MMN } \\
\text { noise }\end{array}$ & $\begin{array}{l}N 2 b \\
\text { quiet }\end{array}$ & $\begin{array}{l}N 2 b \\
\text { noise }\end{array}$ & $\begin{array}{l}\text { P3b } \\
\text { quiet }\end{array}$ & $\begin{array}{c}P 3 b \\
\text { noise }\end{array}$ & $\begin{array}{c}\text { MMN } \\
\text { quiet }\end{array}$ & $\begin{array}{l}\text { MMN } \\
\text { noise }\end{array}$ & $\begin{array}{l}N 2 b \\
\text { quiet }\end{array}$ & $\begin{array}{l}N 2 b \\
\text { noise }\end{array}$ & $\begin{array}{l}\text { P3b } \\
\text { quiet }\end{array}$ & $\begin{array}{c}P 3 b \\
\text { noise }\end{array}$ \\
\hline$d^{\prime}$ & -0.067 & -0.251 & -0.041 & -0.255 & 0.355 & 0.262 & 0.051 & 0.261 & -0.358 & $-0.363^{*}$ & -0.275 & -0.202 \\
\hline RT & 0.265 & 0.158 & 0.005 & 0.126 & -0.221 & -0.168 & 0.351 & 0.059 & 0.246 & 0.084 & 0.169 & 0.139 \\
\hline Delta $f$ & $0.511^{* *}$ & 0.299 & -0.040 & 0.098 & $-0.426^{*}$ & -0.286 & 0.254 & 0.097 & $0.653^{* * *}$ & $0.437^{*}$ & $0.531 * *$ & $0.363^{*}$ \\
\hline $\mathrm{S} / \mathrm{N}$ ratio & $0.376^{*}$ & 0.244 & 0.042 & 0.083 & -0.292 & -0.182 & -0.051 & -0.304 & $0.534^{* *}$ & $0.426^{*}$ & $0.389 *$ & 0.254 \\
\hline
\end{tabular}


result in pronounced changes in the ERPs of the elderly subjects.

\section{Effects of noise}

Auditory processing was negatively affected by the presence of competing noise at all levels from the earlier sensory-perceptual to the later cognitive stages, as indicated by smaller amplitudes and increased latencies for the majority of ERP components. The effect of noise on ERPs corresponded well to the significant decline in behavioral frequency discrimination. In general, and in contrast to what might have been expected, contralateral distracting noise did not affect auditory processing differently in young and elderly listeners, arguing against a susceptibility to the effects of distracting noise specific to age or age-related hearing loss.

A somewhat different and inconsistent response pattern was found for the effect of noise on N1. N1 is known to be related to the audibility of the stimulus. It increases linearly in amplitude with increasing intensity reaching saturation only at relatively high presentation levels (Pfefferbaum et al. 1979; Hyde 1997). Whereas N1 amplitudes were larger in the YNH group with noise in both attention conditions, they decreased in the EHI subjects, regardless of whether they ignored or attended to the stimuli (Fig. 6), indicating that the audibility of the stimuli was reduced by noise and hearing loss.

An intermediate pattern was found in ENH subjects with reduced $\mathrm{N} 1$ amplitudes in the unattended condition and increased amplitudes in the attended condition (Fig. 6). An amplitude increase of N1 has been shown not only by increasing intensity of the stimulus but also by directing attention to the stimuli (Hillyard et al. 1973). The contralateral noise could have acted as an enhancer of the attentional resources directed to target stimuli explaining the larger N1 amplitudes of the YNH and ENH subjects in the attended condition. Interestingly, the young subjects had larger N1 amplitudes in noise even when the auditory input was ignored. This could indicate that young and normal-hearing adults are more able to separate an auditory event from a distracting continuous noise without directing overt attention to it. The lack of a noise-enhanced N1 in the EHI data, even when they attended to the stimuli, suggests that the combined effect of noise and hearing loss on auditory perception could not be compensated for by attentional efforts.

In our study, noise and signals could be easily discriminated based on the stimulus type (cafeteria noise versus pure tones) and auditory channel (right versus left ear). This may have contributed to the lack of specific age-related effects of noise on auditory processing other than N1 amplitude. Studies of selective attention have shown that an age-related deficit may become more evident when the differences between target and distractor are small (Plude et al. 1994; Karayanidis et al. 1995). More difficult test conditions, such as binaural or ipsilateral presentation of stimuli and noise or speech signals instead of pure tones within a speech babble noise, might be more suited to reveal age-specific effects. For example, Tun and Wingfield (1999) showed that age differences in the ability to process spoken language in the presence of background noise emerged only when the noise consisted of one or two competing speakers or a multitalker babble, but not with white noise.

Another possible reason for the lack of a specific age-related noise effect is that the ENH subjects had elevated thresholds for the frequencies from 4 to $8 \mathrm{kHz}$. This high-frequency hearing loss could have decreased the audibility of the noise, facilitating frequency discrimination and masking a hypothetical age-specific susceptibility to a distracting noise.

\section{Effects of age}

In contrast to the weak age-specific noise effect, pronounced age-related changes occurred in the later components of both the standard (Fig. 5) and difference (Fig. 10) ERP waveforms, concerning N2, $\mathrm{N} 2 \mathrm{~b}$, and P3b. Changes in amplitude and latency of the earlier standard components $\mathrm{P} 1, \mathrm{~N} 1$, and P2 and in the MMN were comparatively small or absent. In addition, behavioral performance was not influenced by age alone because the elderly subjects with normal hearing in the test frequencies performed just as well as the young subjects.

N2 in standard waveforms. The most evident agerelated difference in the standard ERP waveforms was the missing N2 in the elderly subjects (Fig. 5). Little is known about the functional significance of this negativity. $\mathrm{N}_{2}$ early lies within the same latency range of 200-350 ms as the sleep N2 or N350, which is observed during drowsiness and sleep. It is considered to reflect a mechanism contrary to attention, preventing conscious processing and facilitating sleep. A recent study from Kallai et al. (2003) provided evidence that the sleep N2 may also emerge during waking conditions if a stimulus is truly ignored. Thus the N2 in the responses to the standard stimuli of the young subjects could reflect the inhibition of the processing of irrelevant information, whereas the lack of $\mathrm{N} 2$ in the elderly could be interpreted as a decrease in the capability to suppress successfully the processing of irrelevant stimuli.

$M M N$ and the positivity following MMN. No significant age effect on MMN amplitudes and latencies was found, although there was a trend toward smaller 
amplitudes and increased latencies. In particular, some discrepancy between statistical analysis and visual inspection was present for the $1032-\mathrm{Hz}$ deviant showing a considerably larger MMN in the difference waveform of the young subjects. This lack of a significant age effect may be due to the intersubject variability of the data and outliers in the groups of young and elderly hearing-impaired subjects. Elderly subjects were less sensitive to the smallest frequency contrast, as indicated by the missing MMN to the $1016-\mathrm{Hz}$ deviant. The current results are in agreement with studies of Gaeta et al. (1998) and Bertoli et al. (2002), which reported also a missing MMN to the smallest deviants along with smaller amplitudes and increased latencies for the elderly subjects. These findings may indicate that automatic preattentive auditory discrimination becomes less sensitive in the elderly.

In contrast to the relatively small age effect on MMN, the positivity following the MMN was highly different between young and elderly subjects (Fig. 7). This component could be interpreted as a P3a. In contrast to the P3b in attended conditions, the P3a is elicited in unattended conditions by larger stimulus contrasts, which induce an involuntary attention shift toward the stimuli. The small stimulus contrasts used in this study and the fact that the positivity inverted polarities at the mastoids, whereas a P3a-like component would not, argue against this interpretation. Based on inspection of the original standard and deviant waveforms, we suggest another explanation. The positivity in the difference waveform may derive either from an increased positivity in the deviant waveform, from an increased negativity in the standard waveform, or both. Figure 12 depicts the grand average waveforms at $\mathrm{Fz}$ elicited by the standard and deviant stimuli. A clear negativity, the $\mathrm{N} 2_{\text {early }}$, can be noted in the standard waveforms of the young subjects in the latency range of the post-MMN positivity. This negativity is more pronounced than the positive deflection in the three deviant waveforms. Thus the post-MMN positivity appears to reflect the pronounced N2 in the young subjects rather than a P3a-like component.

N2b and P3b. The most evident age-related changes in the ERP difference waveforms were found for the late components N2b and P3b (Fig. 10). In contrast to other studies, N2b amplitude was significantly larger in the elderly. The different results might be related to differences in the degree of stimulus contrasts. Typically, large and easily discriminable deviations of the target from the standard stimulus, such as 1 versus $2 \mathrm{kHz}$, have been used in studies reporting smaller (Enoki et al. 1993; Friedman et al. 1993; Iragui et al. 1993; Anderer et al. 1996) or invariant N2bs (Picton et al. 1984; Barrett et al. 1987;

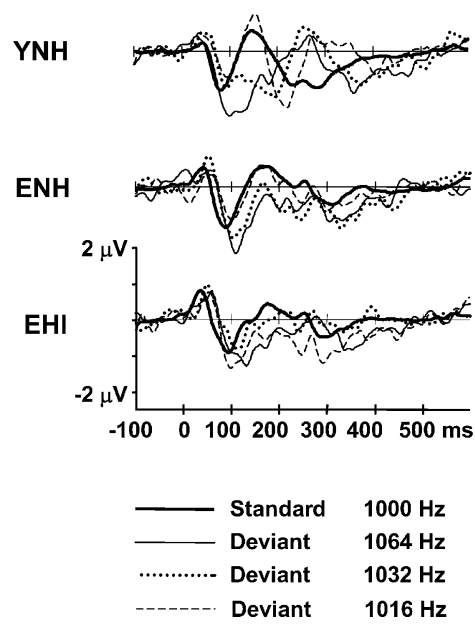

FIG. 12. Grand mean responses to the standard and the three deviant stimuli of the unattended condition at electrode site Fz for the three subject groups.

Amenedo and Diaz 1998b) in the elderly. Fitzgerald and Picton (1983) found that N2b increased significantly with increasing discrimination difficulty. They proposed that $\mathrm{N} 2 \mathrm{~b}$ is controlled much more by attention than by deviance of the stimuli. The N2b can be long and large if the subject considers it worthwhile to allocate much effort to the evaluation of the signals. In this view, the large and delayed N2b of the elderly subjects in the current study could indicate that larger attentional resources had to be directed to the analysis of the target stimulus. The view that N2 amplitude is related to the listener's efforts and/or to the significance the listener attributes to the stimuli is supported by studies performed with cochlear implant users (Okusa et al. 1999) and individuals who became blind at an early age (Kujala et al. 1992). Much larger N2 amplitudes were found in these patients than in normal listeners.

\section{Psychoacoustic performance and ERP data}

Age-related differences in ERP waveforms did not correspond to behavioral performance, whether obtained psychoacoustically in separate sessions or during the ERP measurements. The ENH subjects performed just as well as those in the $\mathrm{YNH}$ group. The discrepancy between behavioral and electrophysiological data is supported by the lack of consistent significant correlations between the two measures, in particular, for N2b and P3b amplitudes (Table 5).

The most consistent significant correlations were found for N2b latencies. This component reflects the early stages of stimulus evaluation and classification processes (Hillyard and Picton 1987). The timing of these processes related to the discrimination of stimuli appears to be the best predictor of behavioral performance. 
In view of the speed and accuracy with which the elderly responded in the behavioral task, it must be concluded that in cognitively healthy and normalhearing elderly subjects, behavioral performance may be well maintained, but that different central auditory processing strategies are used. The reasons for applying different strategies may be functional, structural, or a combination of these two changes in the brain. One major finding of age-related ERP differences was the lack of N2 in the standard response, which was interpreted as a deficit in inhibiting the processing of irrelevant standard information. To compensate for this inhibitory deficit, more attention and time must be employed to evaluate the target stimuli, as indicated by the larger and later N2b. As a consequence, auditory processing becomes more difficult and less efficient, which is reflected by the later and smaller P3b. However, the elderly subjects in our study were still able to perform the task successfully without complaining about being tired or exhausted after testing, as one may have expected from the pronounced ERP changes. This indicates that the elderly's different processing strategies, although being more demanding, can still compensate for the structural changes occurring in the aging brain. One might also argue that ERPs may be suitable for revealing a processing deficit before it is manifested behaviorally.

\section{Effects of hearing loss}

The effect of hearing loss was evaluated by comparing two groups of elderly subjects with different audiometric profiles. Some elevation of hearing thresholds in the high-frequency range is inevitably associated with age, which was also present in our elderly subjects considered to have normal hearing for their age. Their thresholds were comparable to those of the young subjects at the frequencies of the test stimuli. Moreover, they performed just as well on the SPIN test and the behavioral tasks as did the YNH subjects. Although the high-frequency threshold elevation may have had an effect on the distracting noise, there is no evidence for such an influence on ERP or behavioral data.

Overall, hearing-loss-related changes in amplitude and latency of ERP components were relatively small. The ENH and EHI groups differed significantly only in N1 amplitude and N2b latency. Thus age appeared to have a greater impact on ERPs than did hearing loss. Nevertheless, such a conclusion must be made with caution because of the lack of a group of young subjects with comparable hearing loss and because of the possible confounding effect of high-frequency hearing loss in the ENH subjects. The decrease of N1 amplitude in the EHI subjects is in agreement with the sensitivity of the N1 component to the physical representation of the auditory stimulus. A decrease in N1 amplitude has been reported by Wall et al. (1991) in a group of subjects as the only significant effect of mild-to-moderate hearing loss.

\section{CONCLUSIONS}

Based on the results from the psychoacoustic and electrophysiological tests reported here, several factors may contribute to the hearing difficulties of elderly persons. Sensorineural hearing loss clearly deteriorates frequency discrimination and speech perception in noise. Aging, both in subjects with relatively normal hearing and with hearing loss, is associated with pronounced changes of the later cognitive ERP components, reflecting a decrease in inhibitory control of irrelevant stimuli, a decreased sensitivity of automatic preattentive stimulus discrimination, and a more effortful and delayed stimulus evaluation. These results support current concepts of presbycusis suggesting a combination of peripheral, central auditory, and cognitive factors underlying the hearing difficulties of elderly persons.

\section{ACKNOWLEDGMENTS}

This work was supported by grants from Swiss National Science Foundation (Project-No. 3100-063421) and Novartis Foundation.

\section{REFERENCES}

Alain C, Woods DL. Age-related changes in processing auditory stimuli during visual attention: evidence for deficits in inhibitory control and sensory memory. Psychol. Aging 14:507-519, 1999.

Amenedo E, Diaz F. Automatic and effortful processes in auditory memory reflected by event-related potentials. Age-related findings. Electroencephalogr. Clin. Neurophysiol. 108:361-369, 1998 a.

Amenedo E, Diaz F. Aging-related changes in processing of nontarget and target stimuli during an auditory oddball task. Biol. Psychol. 48:235-267, 1998b.

Anderer P, Semlitsch HV, Saletu B. Multichannel auditory eventrelated brain potentials: effects of normal aging on the scalp distribution of N1, P2, N2 and P300 latencies and amplitudes. Electroencephalogr. Clin. Neurophysiol. 99:458-472, 1996.

BARr RA, Giambra LM. Age-related decrement in auditory selective attention. Psychol. Aging 5:597-599, 1990.

Barrett G, Neshige R, Shibasaki H. Human auditory and somatosensory event-related potentials: effects of response condition and age. Electroencephalogr. Clin. Neurophysiol. 66:409-419, 1987.

Bertoli S, Smurzynski J, Probst R. Temporal resolution in young and elderly subjects as measured by mismatch negativity and 
a psychoacoustic gap detection task. Clin. Neurophysiol. 113:396-406, 2002.

Chao LL, KNight RT. Prefrontal deficits in attention and inhibitory control with aging. Cereb. Cortex 7:63-69, 1997.

Committee on Hearing B, and Biomechanics (CHABA): Working Group on Speech Understanding and Aging. Speech understanding and aging. J. Acoust. Soc. Am. 83:859-895, 1988.

CRANFord JL, Martin DR. Age-related changes in binaural processing: I. Evoked potential findings. Am. J. Otol. 12:357-364, 1991.

Cunningham J, Nicol T, Zecker SG, Bradlow A, Kraus N. Neurobiologic responses to speech in noise in children with learning problems: deficits and strategies for improvement. Clin. Neurophysiol. 112:758-767, 2001.

Czigler I, Csibra G, Csontos A. Age and inter-stimulus interval effects on event-related potentials to frequent and infrequent auditory stimuli. Biol. Psychol. 33:195-206, 1992.

Enoki H, Sanada S, Yoshinaga H, Oka E, Ohtahara S. The effects of age on the N200 component of the auditory event-related potentials. Brain Res. Cogn. Brain Res. 1:161-167, 1993.

Fisher AL, Hymel MR, Cranford JL, DeChicchis AR. Electrophysiologic signs of auditory distraction in elderly listeners. J. Am. Acad. Audiol. 11:36-45, 2000

Fitzgerald PG, Picton TW. Event-related potentials recorded during the discrimination of improbable stimuli. Biol. Psychol. 17:241-276, 1983.

Ford JM, Pfefferbaum A. Event-related potentials and eyeblink responses in automatic and controlled processing: effects of age. Electroencephalogr. Clin. Neurophysiol. 78:361-377, 1991.

Friedman D, Simpson G, Hamberger M. Age-related changes in scalp topography to novel and target stimuli. Psychophysiology 30:383-396, 1993.

Friedman D, Kazmerski VA, Cycowicz YM. Effects of aging on the novelty P3 during attend and ignore oddball tasks. Psychophysiology 35:508-520, 1998.

Frisina DR, Frisina RD. Speech recognition in noise and presbycusis: relations to possible neural mechanisms. Hear. Res. 106:95-104, 1997.

Gaeta H, Friedman D, Ritter W, Cheng J. An event-related potential study of age-related changes in sensitivity to stimulus deviance. Neurobiol. Aging 19:447-459, 1998.

Guthrie D, Buchwald JS. Significance testing of difference potentials. Psychophysiology 28:240-244, 1991.

HASHER L, ZACKS RT. Working memory, comprehension, and aging: a review and a new view. In: Bower GH (ed) The Psychology of Learning and Motivation. Academic Press, San Diego, CA, pp 225-293, 1988.

Hayes EA, Warrier CM, Nicol TG, Zecker SG, Kraus N. Neural plasticity following auditory training in children with learning problems. Clin. Neurophysiol. 114:673-684, 2003.

Hillyard SA, Picton TW. Electrophysiology of cognition. In: Higher Functions of the Nervous System. American Physiological Society, Bethesda, MD, pp 519-584, 1987.

Hillyard SA, Hink RF, Schwent VL, Picton TW. Electrical signs of selective attention in the human brain. Science 182:177-180, 1973.

HydE M. The N1 response and its applications. Audiol. Neuro-otol. 2:281-307, 1997.

Hymel MR, Cranford JL, Stuart A. Effects of contralateral speech competition on auditory event-related potentials recorded from elderly listeners: brain map study. J. Am. Acad. Audiol. 9:385-397, 1998.

Iragui VJ, Kutas M, Mitchiner MR, Hillyard SA. Effects of aging on event-related brain potentials and reaction times in an auditory oddball task. Psychophysiology 30:10-22, 1993.

Kalikow DN, Stevens KN. Development of a test of speech intelligibility in noise using sentence materials with controlled word predictability. J. Acoust. Soc. Am. 61:1337-1351, 1977.

Kallai I, Harsh J, Voss U. Attention to external stimuli during wakefulness and sleep: evoked $40-\mathrm{Hz}$ response and N350. Psychophysiology 40:955-966, 2003.

Karayanidis F, Andrews S, Ward PB, Michie PT. ERP indices of auditory selective attention in aging and Parkinson's disease. Psychophysiology 32:335-350, 1995.

Kujala T, Alho K, Paavilainen P, Summala H, Nä̈ätänen R. Neural plasticity in processing of sound location by the early blind: an event-related potential study. Electroencephalogr. Clin. Neurophysiol. 84:469-472, 1992.

Martin BA, Kurtzberg D, Stapells DR. The effects of decreased audibility produced by high-pass noise masking on N1 and the mismatch negativity to speech sounds $/ \mathrm{ba} / \mathrm{and} / \mathrm{da}$. J. Speech Lang. Hear. Res. 42:271-286, 1999.

McDowd JM, Filion DL. Aging, selective attention, and inhibitory processes: a psychophysiological approach. Psychol. Aging 7:65-71, 1992.

Moore BC, Peters RW. Pitch discrimination and phase sensitivity in young and elderly subjects and its relationship to frequency selectivity. J. Acoust. Soc. Am. 91:2881-2893, 1992.

Muller-Gass A, Marcoux A, Logan J, Campbell KB. The intensity of masking noise affects the mismatch negativity to speech sounds in human subjects. Neurosci. Lett. 299:197-200, 2001.

Novitski N, Alho K, Korzyukov O, Carlson S, Martinkauppi S, Escera C, Rinne T, Aronen HJ, NäÄTänen R. Effects of acoustic gradient noise from functional magnetic resonance imaging on auditory processing as reflected by event-related brain potentials. NeuroImage 14:244-251, 2001.

Oates PA, Kurtzberg D, Stapells DR. Effects of sensorineural hearing loss on cortical event-related potential and behavioral measures of speech-sound processing. Ear Hear. 23:399-415, 2002.

Okusa M, Shiraishi T, Kubo T, Nageishi Y. Effects of discrimination difficulty on cognitive event-related brain potentials in patients with cochlear implants. Otolaryngol. Head Neck Surg. 121: 610-615, 1999.

Pekkonen E. Mismatch negativity in aging and in Alzheimer's and Parkinson's diseases. Audiol. Neuro-otol. 5:216-224, 2000.

Pfefferbaum A, Ford JM, Roth WT, Hopkins WF III, Kopell BS. Event-related potential changes in healthy aged females. Electroencephalogr. Clin. Neurophysiol. 46:81-86, 1979.

Picton TW, Stuss DT, Champagne SC, Nelson RF. The effects of age on human event-related potentials. Psychophysiology 21: 312-325, 1984.

Plude DJ, Enns JT, Brodeur D. The development of selective attention: a life-span overview. Acta Psychol. (Amst.) 86:227272, 1994

Polen S. Auditory event related potentials. Semin. Hear. 5:127-141, 1984.

Polich J. Meta-analysis of P300 normative aging studies. Psychophysiology 33:334-353, 1996.

Salisbury DF, Desantis MA, Shenton ME, McCarley RW. The effect of background noise on P300 to suprathreshold stimuli. Psychophysiology 39:111-115, 2002.

Salo SK, Lang AH, Salmivalli AJ. Effect of contralateral white noise masking on the mismatch negativity. Scand. Audiol. 24: 165-173, 1995.

Sams M, Paavilainen P, Alho K, Nä̈̈̈änen R. Auditory frequency discrimination and event-related potentials. Electroencephalogr. Clin. Neurophysiol. 62:437-448, 1985.

Seidel H, Bluthner R, Martin J, Menzel G, Panuska R, Ullsperger P. Effects of isolated and combined exposures to whole-body vibration and noise on auditory-event related brain potentials and psychophysical assessment. Eur. J. Appl. Physiol. Occup. Physiol. 65:376-382, 1992.

SwETs JA. Signal Detection and Recognition by Human Observers. Wiley, New York, 1964.

Thalmann B, Monsch AU, Schneitter M, Bernasconi F, Aebi C, 
Woods DL, Staehelin HB. The cerad neuropsychological assessment battery (Cerad-NAB) - a minimal data set as a common tool for German-speaking Europe. Neurobiol. Aging 21:30, 2000.

Tremblay KL, Piskosz M, Souza P. Effects of age and age-related hearing loss on the neural representation of speech cues. Clin. Neurophysiol. 114:1332-1343, 2003.

Tremblay KL, Billings C, Rohila N. Speech evoked cortical potentials: effects of age and stimulus presentation rate. J. Am. Acad. Audiol. 15:226-237, 2004.

TsсHOpP K, Züst H. Performance of normally hearing and hearingimpaired listeners using a German version of the SPIN-Test. Scand. Audiol. 23:241-247, 1994.

Tun PA, Wingfield A. One voice too many: adult age differences in language processing with different types of distracting sounds. J. Geront., Ser. B Psychol. Sci. Soc. Sci. 54:317-327, 1999.
Wall LG, Dalebout SD, Davidson SA, Fox RA. Effect of hearing impairment on event-related potentials for tone and speech distinctions. Folia Phoniatr. 43:265-274, 1991.

Welsh KA, Butters N, Mohs RC, Beekly D, Edland S, Fillenbaum G, Heyman A. The Consortium to Establish a Registry for Alzheimer's Disease (CERAD). Part V. A normative study of the neuropsychological battery. Neurology 44:609-614, 1994.

Whiting KA, Martin BA, Stapells DR. The effects of broadband noise masking on cortical event-related potentials to speech sounds /ba/ and /da/. Ear Hear. 19:218-231, 1998.

Wible B, Nicol T, Kraus N. Abnormal neural encoding of repeated speech stimuli in noise in children with learning problems. Clin. Neurophysiol. 113:485-494, 2002.

Woons DL. Auditory selective attention in middle-aged and elderly subjects: an event-related brain potential study. Electroencephalogr. Clin. Neurophysiol. 84:456-468, 1992. 